\title{
Assessment of possibility of metal waterjet cutting wastes use in building materials production
}

\author{
Nataliya Skanavi ${ }^{1}$, and Timofey Dovydenko ${ }^{1, *}$ \\ ${ }^{1}$ Moscow state university of civil engineering, Yaroslavskoye shosse, 26, Moscow, Russia, 129337
}

\begin{abstract}
The paper is aimed at studying the composition and properties of the wastes generated during metal waterjet cutting and assessing the possibility of their use in building materials production. The essence of waterjet cutting process, waste generation mechanism, waste accumulation volumes at enterprises are described. The composition and properties of the used abradant - garnet sand is given and the features of its destruction during cutting are revealed. Waterjet cutting wastes are comprehensively studies: average and bulk density, granulometric composition, chemical composition are determined, various fractions are studied with an electronic microscope. It is revealed that during cutting abradant particles are destroyed, a large amount of dust fraction emerges with the particles of cut metal mixed into it. The metal waterjet cutting wastes are found to be very small, practically monofractive, heavy sands with a high content of dust fraction, which chemical composition is dominated by oxides of iron, silicon and aluminum. This characteristic of the wastes has allowed us to outline possible ways of how to use them: in ceramic items production as thinning agents and fluxing agents, in Portland cement production as a correcting iron-containing agent, as a mortar filler, including special mortars, as a building materials volumetric staining pigment, etc.
\end{abstract}

\section{Introduction}

\subsection{Study goal}

The use of industrial and consumption wastes is one of the most important areas in environmental protection directly related to natural resources preservation and biosphere contamination prevention. The total amount of accumulated and recorded wastes in Russia as a whole is approximately 31.5 bln tons [1]. The vast majority of accumulated and identified wastes is classified under Hazard Class 5, that is, as non-hazardous - 31.1 bln tons, or almost $99 \%$ of their total volume. In 2015, industrial and consumption wastes in Russia were generated in the amount of 5,060.2 mln tons, 4,950.2 mln tons of which were of Hazard Class 5. These figures are close to average annual values. To store such amount of wastes, hundreds of thousands of hectares of land are taken from the economic turnover.

Corresponding e-mail: dovydenkotimofei@gmail.com 
Necessary storage of wastes, arrangement and maintenance of waste dumps require huge expenditures, while the wastes concentrated in dumps, storages, junkyards pollute soil, atmospheric air, surface and ground waters, suppress flora and fauna. All the business costs associated with operation of relevant facilities, plants, machinery and equipment are included in products prime cost.

In 2015 , the level of non-hazardous wastes use was approximately $52 \%$, which was extremely inadequate. Therefore, study and involvement of new, previously unused wastes in production is an urgent task. Even the wastes generated in small amounts can fill the gap in resource deficit for production of a particular material. The paper is aimed at studying the composition and properties of the wastes generated during metal waterjet cutting and assessing the possibility of their use in building materials production.

\subsection{Waterjet cutting principle and waste generation}

Waterjet cutting is a process when a material is exposed to a high-speed jet of water mixed with an abradant $[2,3,4,5]$. The functional concept of this type of cutting is that when passing through a hole of $0.2 \ldots 0.8 \mathrm{~mm}$ in diameter a water flow accelerates up to about $300 \ldots 900 \mathrm{~m} / \mathrm{s}$, mixes with an abradant and is applied to the surface to be cut under a high pressure $(200 \ldots 600 \mathrm{MPa})$. At the instant of collision with the material, jet kinetic energy transforms into mechanical energy of micro-destruction of the processed material, thus cutting it.

Various materials (ferrous and non-ferrous metals, alloys, ceramics [6], glass, natural stone, plastics, etc.) are cut with the use of this method, but metal waterjet cutting is of greater interest.

Waterjet cutting advantages as compared to other types of cutting (gas-oxygen, plasmaarc, laser cutting) are as follows: low operating temperature in the cutting zone $\left(60 \ldots 90^{\circ} \mathrm{C}\right)$, no thermal impact on the material, low material consumption factor (cutting width of $0.2 \ldots 3$ $\mathrm{mm}$ ), large thickness of cut work pieces (up to $300 \mathrm{~mm}$ and above), no impact on alloyed steels chemical composition, possibility of cutting thin sheet materials stacked in several layers, high process safety due to absence of flammable and explosive substances, environmental friendliness of the process, high quality of treated surface which often requires no additional machining, etc.

Garnet sand is used as an abradant [7]. Garnets are a vast group of minerals which are chemically related to the so-called orthosilicates. Various mineral types are marked out of garnets group, of which ferrous-aluminum garnet - almandine $\mathrm{Fe}_{3} \mathrm{Al}_{2}\left(\mathrm{SiO}_{4}\right)_{3}$ is used in waterjet cutting. This mineral is of a cherry-red color with a high hardness of $7 \ldots 8$ on the Mohs scale, high density of $4.1 \ldots 4.3 \mathrm{~g} / \mathrm{cm}^{3}$, very high destruction resistance, and no toxicity to humans and environment. The garnet sand is mainly produced in India, Australia, South Africa, and Czech Republic.

The waterjet cutting process generates slurry wastes containing garnet sand, particles of the material being cut and water. The slurry is dehydrated, the dry residue is stored within the territory of an enterprise, and is transported to solid domestic waste landfills when accumulated in sufficient amounts.

One medium-powered waterjet cutting machine (Water Jet Sweden NC3015) produces approximately 200 grams of dry waste per minute. The machine is operated round-theclock and its useful working time amounts to $70 \ldots 80 \%$ (the rest of time is readjustment, cleaning, etc.). Thus, even with one waterjet cutting machine operated, an enterprise produces more than $200 \mathrm{~kg}$ of wastes per day. In consideration of decisive advantages of waterjet cutting as compared to other types of cutting, its share in metal cutting area will increase, so will the amount of wastes generated. This challenges enterprises to store and recycle the wastes. 


\section{Study objects and methods}

\subsection{Garnet abradant}

We examined the garnet sand of one of the main Russian suppliers R-Garnet CJSC, which had developed garnet abradant specifications [8]. Sand moisture content was $1.5 \%$, bulk density $-2.31 \mathrm{~g} / \mathrm{cm}^{3}$, grains density $-3.805 \mathrm{~g} / \mathrm{cm}^{3}$, intergrain porosity $-39.29 \%$. The sand was pure, with no organic impurities.

The granulometric composition determined with the use of standard sand sieves (listed in the table) showed no particles larger than $0.63 \mathrm{~mm}$. The fineness modulus was 1.752 .

Particles of different sizes with sharp edges were made by crushing the rock. Sand with particle sizes of $180 \ldots 300 \mu \mathrm{m}$ is used for waterjet cutting. With the use of one cutting head abradant consumption, depending on the material to be cut, ranged from $50 \mathrm{~g} / \mathrm{min}$ (for plastics) and $160 \ldots 200 \mathrm{~g} / \mathrm{min}$ (for glass) to $300 \ldots 450 \mathrm{~g} / \mathrm{min}$ (for steel). Approximate chemical composition of the garnet sand (produced by Garnet "MICROBLAST"), wt \%: $\mathrm{SiO}_{2}-31.00 \%, \mathrm{Al}_{2} \mathrm{O}_{3}-21.60 \%, \mathrm{Fe}_{2} \mathrm{O}_{3}-37.00 \%, \mathrm{MgO}-7.40 \%$, with $1.84 \%, \mathrm{TiO}_{2}-$ $0.55 \%$, as well as chlorides, $\mathrm{Na}_{2} \mathrm{O}, \mathrm{K}_{2} \mathrm{O}, \mathrm{MnO}_{2}, \mathrm{P}_{2} \mathrm{O}_{5}$ etc. In terms of mineral composition, this sand is composed of $96.9 \%$ of garnet, $2.4 \%$ of ilmenite, $0.4 \%$ of quartz.

\subsection{Metal waterjet cutting wastes}

The ferrous metals waterjet cutting wastes of SK Modul LLC (Khimki city) have been examined. The results are as follows: true density is $3.7 \mathrm{~g} / \mathrm{cm}^{3}$, bulk density is $2.2 \mathrm{~g} / \mathrm{cm}^{3}$. The granulometric composition has been determined with the use of standard sand sieves, and a fraction of less than $0.16 \mathrm{~mm}$ has been sieved through the 008 sieve.

Table 1. Comparison of the granulometric composition of the original abradant and waterjet cutting waste $\mathrm{s}$

\begin{tabular}{|c|c|c|c|c|}
\hline \multirow{2}{*}{$\begin{array}{c}\text { Sieve hole } \\
\text { dimensions, (mm) }\end{array}$} & \multicolumn{2}{|c|}{ Garnet abradant } & \multicolumn{2}{c|}{ Waterjet cutting wastes } \\
\cline { 2 - 5 } & $\begin{array}{c}\text { Individual } \\
\text { residues, \% }\end{array}$ & Full residues, \% & $\begin{array}{c}\text { Individual } \\
\text { residues, \% }\end{array}$ & Full residues, \% \\
\hline 0.315 & 75.6 & 75.6 & 1.6 & 1.6 \\
\hline 0.16 & 24 & 99.6 & 70.5 & 72.1 \\
\hline Less than 0.16 & 0.3 & 99.9 & 27.1 & 99.2 \\
\hline Total & 99.9 & - & 99.2 & - \\
\hline
\end{tabular}

To identify the processes occurring during waterjet cutting with abradant and cut metal, and accordingly, the process of cutting wastes composition generation, a microscopic study of individual waste fractions and determination of their chemical (elemental) composition was performed using spectral analysis method.

\section{Results}

\subsection{Granulometric composition}

The table shows that large particles (larger than $0.315 \mathrm{~mm}$ ) of the original abradant are destroyed during metal cutting. A large number of small $(0.16 \ldots 0.315 \mathrm{~mm})$ and minute (less than $0.16 \mathrm{~mm}$ ) particles emerge. However, such a change in granulometric composition is also due to the fact that the particles of the metal being cut join the minute dust fraction. 
The dust fraction has been sieved through the 008 sieve, and the residue on it is $31.3 \%$. That is, $69 \%$ of the dust fraction particles are less than $80 \mu \mathrm{m}$, which is comparable with the Portland cement particles size.

\subsection{Microscopic examination}

The assumption that the cut metal particles enter exactly into the dust fraction has been confirmed by the wastes microscopic examination and chemical element analysis results.

The microscopic examination has shown that the particles ranging in size from 0.16 to $0.315 \mathrm{~mm}$ are of "crushed stone", irregular shape, of different sizes, and are destroyed garnet sand. During destruction new abrasive sides emerge and sometimes the garnet abradant is used repeatedly by returning it to production again [9].

Fig. 1 shows a micrograph of $0.08 \ldots 0.16 \mathrm{~mm}$ fraction waste particles. Larger particles of destroyed abradant grains, covered with minute particles - products of cut metal destruction, are seen. The fact that the minute fraction is mainly metal is confirmed by particles shape and structure (Fig.2). The particles are of leaf-shaped, layered structure with sharp edges. The particles are relatively uniform in size and structure, their size is about 90 $\mu \mathrm{m}$.

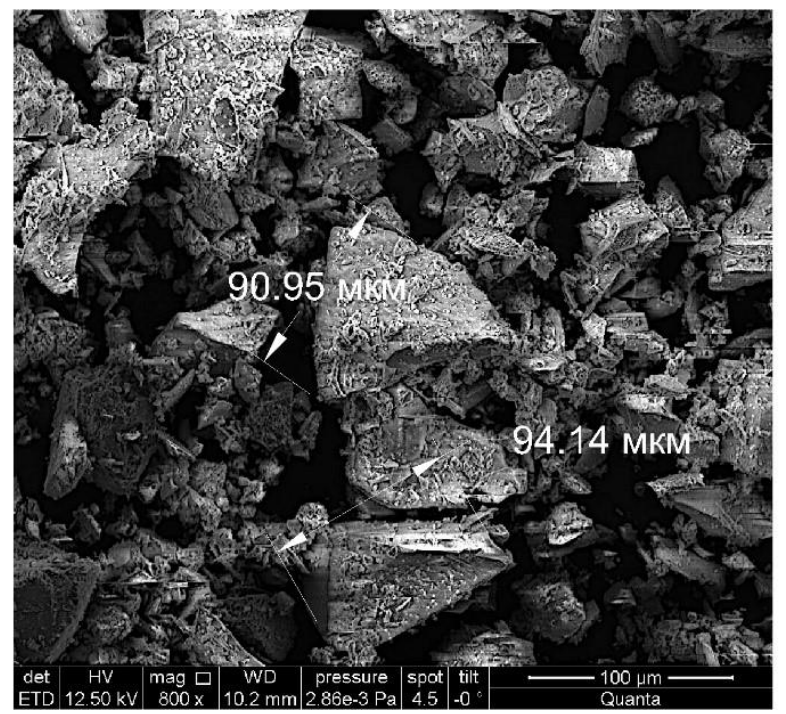

\section{мкм}

$\mu \mathrm{m}$

Fig.1. Micrograph of metal waterjet cutting wastes, fraction $0.08 \ldots 0.16 \mathrm{~mm}$, x800 


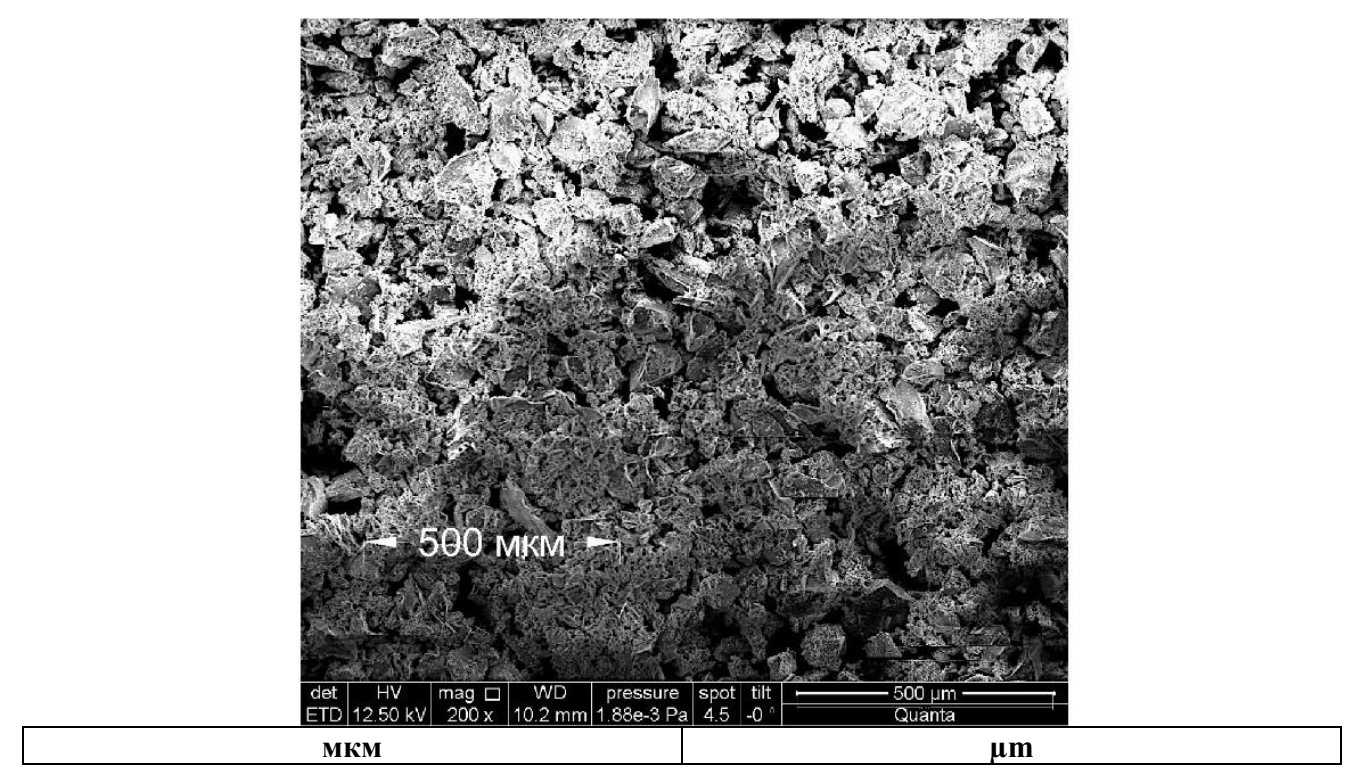

Fig.2. Micrograph of fraction less than $0.08 \mathrm{~mm}$, x200

\subsection{Chemical composition}

The chemical composition determined by spectral analysis confirms a high content of iron oxide $\mathrm{Fe}_{2} \mathrm{O}_{3}$ in the wastes - over $35 \%$ (Fig.3). It can be higher than in the original abradant due to the cut metal destruction products. In terms of iron content, these wastes meet or exceed pyrite cinders and other iron-containing industrial wastes [10, 11]. The following substances are also present in significant quantities: $\mathrm{SiO}_{2}-31.02 \%, \mathrm{Al}_{2} \mathrm{O}_{3}-17.22 \%, \mathrm{TiO}_{2}$ $-7.62 \%, \mathrm{MgO}-6.74 \%$, etc. Titanium dioxide appears in cut steel wastes; in the original abradant its content is only $0.55 \%$. Titanium dioxide in wastes is worth of special study. 


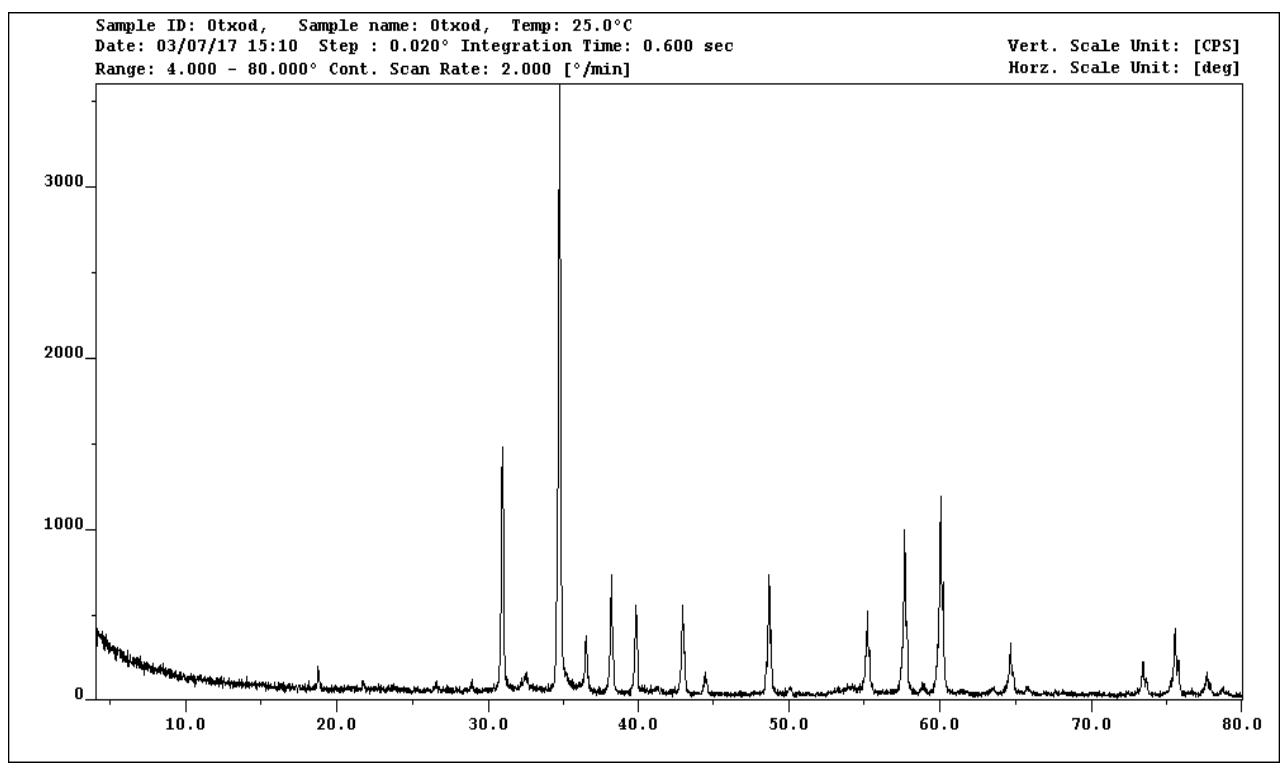

Fig.3. Diffractogram of waste

Based on the metal waterjet cutting wastes composition and properties comprehensive study we can describe them as follows.

These are very small, practically monofractive, heavy sands with a high content of dust fraction, which chemical composition is dominated by oxides of iron, silicon and aluminum.

\subsection{Pilot study of waterjet cutting wastes behavior during firing}

To study the waterjet cutting wastes (mainly metal component) behavior during firing in ceramic mixture composition, sample cubes with an edge of $5 \mathrm{~cm}$ have been made. A lean montmorillonite clay with the following mineral composition has been used: quartz $-49 \%$, montmorillonite $-25 \%$, hydromica $-7 \%$, microcline $-5 \%$, kaolinite $-3 \%$, hematite $-2 \%$, anorthite $-1 \%$, amorphous phase $-8 \%$. [12]. Test composition of ceramic mixture: $50 \%$ of clay and $50 \%$ of wastes. Water-solid ratio was......\%, which corresponded to the water content during production of plastic molded items. The mixture was laid into a mold without compaction. Samples were dried at a temperature of $105^{\circ} \mathrm{C}$, and then exposed to firing at $900^{\circ} \mathrm{C}$.

No deformation of the samples, cracking, color anomalies were observed during firing. The average sample density after firing was... $2.4 \mathrm{~g} / \mathrm{cm}^{3}$, water absorption $-11.6 \%$, compressive strength $-11.46 \mathrm{MPa}$, which corresponded to the brand 125 . The samples' color was red.

Preliminary study allows to conclude about possible use of metal waterjet cutting wastes for ceramic items production: as a thinning agent for ductile clays, for staining of a ceramic piece (due to large content of chromophore - iron oxide and cherry-red mineral almandine, which is included in the wastes). High average density is not a negative factor in floor tiles, clinker ceramics production. High content of iron compounds suggests possible use of these wastes as a fluxing agent. 


\section{Conclusion}

Our study and the data from other sources make it possible to classify the metal waterjet cutting wastes under Hazard Class 5, that is, as non-hazardous [13]. We have started exploring possible use of these wastes in the following areas:

- in building ceramics production - as a thinning agent and fluxing agent, staining component;

- in cements production - as a correcting iron-containing agent for production of Portland cement clinker as a component of the raw mixtures used to produce high-iron cements;

- as a filler in general mortars and special solutions;

- as a pigment for building materials staining; [14]

- other ways of disposal are also considered.

Looking through the publications on the use of wastes does not result in revealing any information on the use of waterjet cutting wastes, which may be due to the lack of interest in the wastes generated in small amounts. We consider it necessary to seek possibilities of using not only the so-called large-tonnage industrial wastes, but also the wastes generated in moderate amounts, which also contributes to solving the problems of resource saving and environmental protection.

The study was carried out with the support of the Principal Regional Center of Collective Use of Moscow State University of Civil Engineering (National Research University).

\section{References}

1. N. G. Rybalsky, E. V. Muravyeva, D. A. Boriskin, About a state and about environmental protection in the Russian Federation in 2015 (Moscow, 2016)

2. M. Hashish, D.E. Steele, D.H. Bothell, Int'1. J. of M/C Tools and Mfg. 37, 465-479 (1997)

3. G. V. Borovsky, S. N. Grigoriev, A. R. Maslov, Modern technologies of processing of materials (Moscow, 2015)

4. I. I. Sazanov, A. M. Lyadnik, S. V. Lyadnik, Tech. ME. 3, 11-14 (2013)

5. D. Krajcarz, Procedia Engineering, 69, 838-843 (2014)

6. P. Gudimetla, J. Wang, W. Wong, J. of Mat. Proc. Tech. 128, 123-129, (2002)

7. D. Begic-Hajdarevic, A. Cekic, M. Mehmedovic, A. Djelmic, Procedia Engineering, 100, 394-399 (2015)

8. TU 3988-002-76245879-2011 Garnet abrasive. Specifications.

9. M. Kantha Babu, O.V. Krishnaiah Chetty, Wear, 254, 763-773 (2003)

10. I. Netinger Grubeša, I. Barišić, A. Fucic, S.S. Bansode, Characteristics and Uses of Steel Slag in Building Construction (2016)

11. M.L.S. Oliveira, C.R. Ward, M. Izquierdo, C.H. Sampaio, I.A.S. de Brum, R.M. Kautzmann, S. Sabedot, X. Querol, L.F.O. Silva, Sci. of The Tot. Env. 430, 34-47 (2002)

12. D.Yu. Zemlyanushnov, V. N. Sokov, D. V. Oreshkin, N. A. Skanavi, Messenger of INRTU, 92, 122-126 (2014)

13. L. I. Dvorkin, O. L. Dvorkin, Construction materials from industry waste (Rostov-naDonu, 2007)

14. A. Yu. Stolboushkin, S. V. Druzhinin, T. I. Storozhenko, V. F. Zavadsky, Consrt. Mat., 5, 95-97 (Moscow, 2008) 